\title{
Ocular threat in juvenile idiopathic arthritis (JIA)
} I Marvillet*1,2,3, C Terada ${ }^{1}$, P Quartier ${ }^{1}$, Bui Quock E ${ }^{1}$, B Bodaghi ${ }^{1}$ and A Prieur ${ }^{1}$

\author{
Address: ${ }^{1}$ Pediatric Rheumatology, Hopital Necker Enfants Malades, Paris, France, ${ }^{2}$ Ophtalmology, Hopital La Pitié, Paris, France and \\ 3Ophtalmology, Hopital Necker Enfants Malades, Paris, France \\ * Corresponding author
}

from I5th Paediatric Rheumatology European Society (PreS) Congress

London, UK. 14-17 September 2008

Published: 15 September 2008

Pediatric Rheumatology 2008, 6(SuppI I):P83 doi:I0.I I86/I546-0096-6-SI-P83

This abstract is available from: http://www.ped-rheum.com/content/6/SI/P83

(C) 2008 Marvillet et al; licensee BioMed Central Ltd.

\section{Background}

Chronic Uveitis (CU) is a severe complication of JIA. We reviewed the clinical course of CU in our JIA patients.

\section{Materials and methods}

Retrospective study of medical records of JIA children with CU, from July 1997 to July 2007.

\section{Results}

Seventy five children out of 715 children followed for JIA presented CU, 69 medical records were analysed. No CU was detected in systemic, RF positive and psoriatic JIA. Sixty CU were observed in 352 oligarticular JIA subtype, 7 in 122 polyarticular and 2 in ERA JIA subtype. $70 \%$ of CU were bilateral. Seventy eight percent of CU were diagnosed at systemic examination. CU was anterior in 41 patients and a panuveitis was diagnosed in 18. Complications were observed in 42 patients (61\%), and in 29 of them, complications were present at diagnosis. Synechia, hyperpressure and band keratopathy were the most frequent complications. Marked visual loss $(<5 / 10)$ was present at first eye examination in 20 children (29\%) ( $50 \%$ were bilateral cases). At last examination, visual loss was present in 14 children (20\%), and 3 children (4\%) were blind. Medical treatment consisted in local steroids, mydriatics, systemic corticosteroids, methotrexate and antiTNF drugs. Twenty-one children underwent surgical treatment. At final examination, only 11 children had presented a favourable outcome. An unfavourable outcome, defined as the need of multiple surgical episodes, was observed in 21 patients. A chronic course with flares is still present in the other 37 patients.

\section{Conclusion}

$\mathrm{CU}$ is a severe complication of JIA. Eye examination is extremely important, particularly in oligo/polyarticular subtype with ANA and must be done systematically in all children as soon as JIA is suspected. 